\title{
Garber, Klaus, Literatur und Kultur im Europa der Frühen Neuzeit. Gesammelte Studien
}

\section{Anne Saada}

\section{OpenEdition}

\section{Journals}

Édition électronique

URL : http://journals.openedition.org/ifha/6493

DOI : $10.4000 /$ ifha. 6493

ISSN : 2198-8943

\section{Éditeur}

IFRA - Institut franco-allemand (sciences historiques et sociales)

Référence électronique

Anne Saada, «Garber, Klaus, Literatur und Kultur im Europa der Frühen Neuzeit. Gesammelte Studien », Revue de I'IFHA [En ligne], Date de recension, mis en ligne le 01 janvier 2012, consulté le 22 septembre 2020. URL : http://journals.openedition.org/ifha/6493 ; DOI : https://doi.org/10.4000/ifha.6493

Ce document a été généré automatiquement le 22 septembre 2020

(CIFHA 


\title{
Garber, Klaus, Literatur und Kultur im Europa der Frühen Neuzeit. Gesammelte Studien
}

\author{
Anne Saada
}

1 Sous le vaste titre de "Littérature et culture en Europe à l'époque moderne ", K. G. présente au lecteur vingt-et-un articles, dont dix-neuf ont déjà été édités entre 1977 et 1999 ( 7 avant 1990 et 9 entre 1990 et 1998). L'intérêt de ce volume, outre sa thématique vaste et incontestable, pourrait résider dans un commentaire critique de l'auteur qui, faisant retour sur son œuvre, expliquerait comment la compréhension de son objet s'est déplacée entre hier et aujourd'hui. Mais telle n'est visiblement pas la perspective de l'auteur. L'absence d'introduction et de conclusion rend d'ailleurs malaisée la saisie de la visée de l'ouvrage, à moins qu'il s'agisse seulement d'offrir au lecteur dans un même volume des études jusqu'ici dispersées.

Anne Saada (CNRS-UMR 8547) 